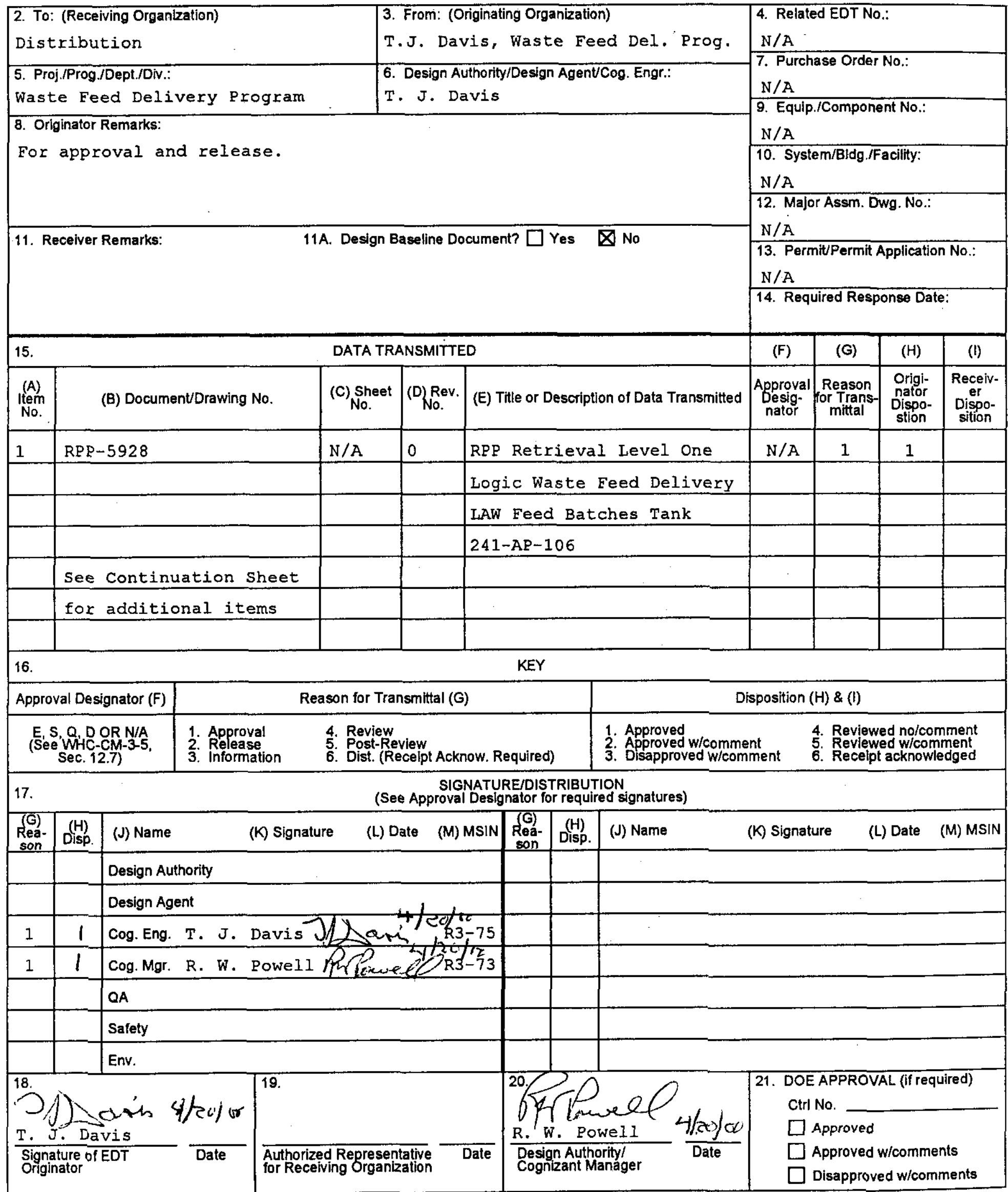




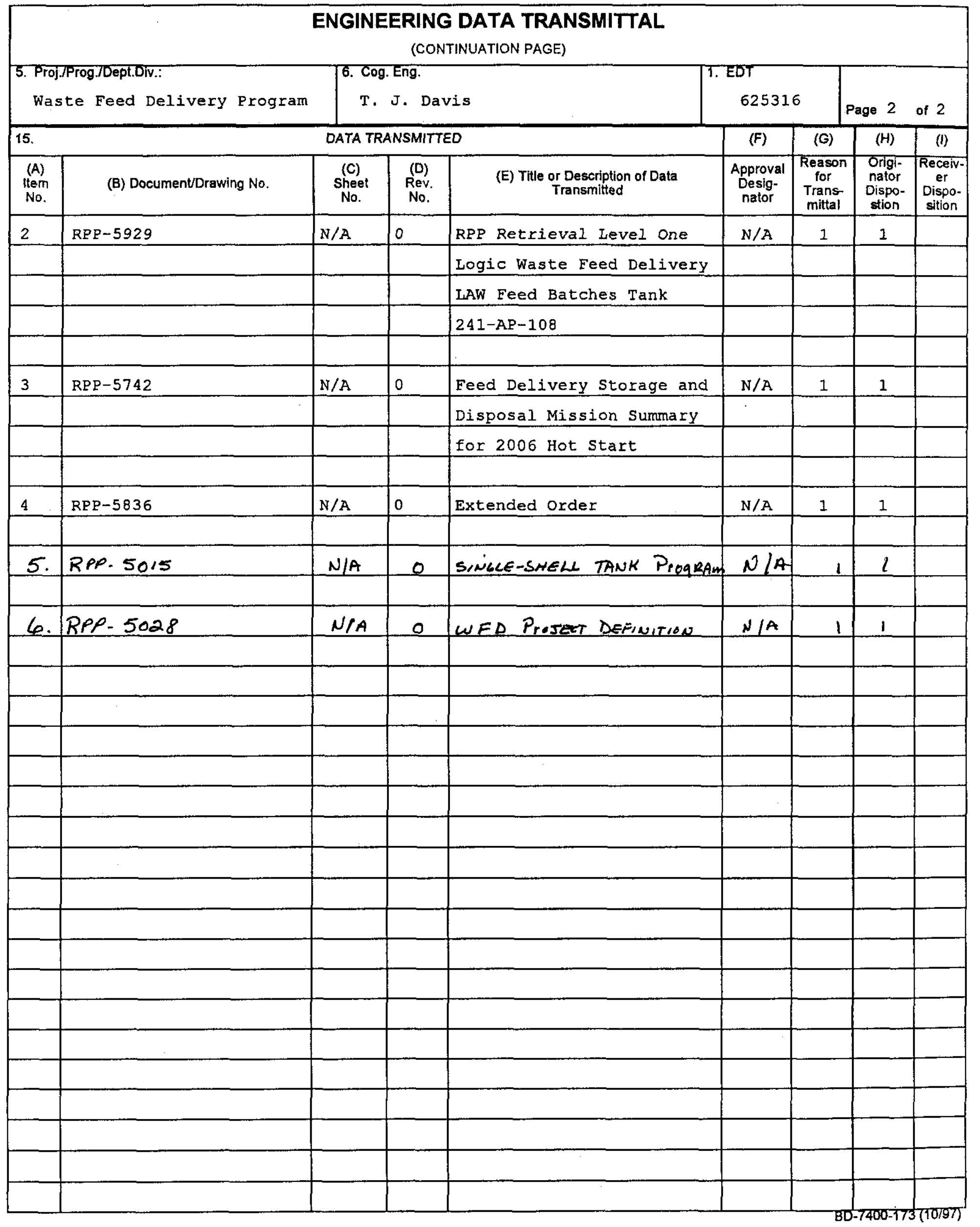




\section{DISTRIBUTION SHEET}

To

Distribution

Project Title/Work Order

See Below

\begin{tabular}{l}
\hline Name \\
\hline Central Files \\
\hline DOE Reading Room \\
\hline DIMC \\
\hline T. J. Davis \\
\hline RPP-5928, Rev. 0 - RPP Retrieval Level One \\
\hline Logic Waste Feed Delivery LAW Feed Batches \\
\hline Tank 241-AP-106 \\
\hline \\
\hline RPP-5929, Rev. 0 - RPP Retrieval Level One \\
\hline Logic Waste Feed Delivery LAW Feed Batches. \\
\hline Tank 241-AP-108 \\
\hline \\
\hline RPP-5742, Rev. 0 - Feed Delivery Storage \\
\hline and Disposal Mission Summary for 2006 Hot \\
\hline Start \\
\hline
\end{tabular}

RPP-5836, Rev. 0 - Extended Order

RPP-5675, REV.O SST prognam

$R P P-5028, R E V .0$ W PROSE<T DEFINITON
From

T. J. Davis, Waste Feed Delivery

Page 1 of 1

Date $4 / 17 / 00$

EDT No. 625316

ECN No. N/A

\begin{tabular}{|c|c|c|c|c|}
\hline MSIN & $\begin{array}{c}\text { Text } \\
\text { With All } \\
\text { Attach. }\end{array}$ & Text Only & $\begin{array}{c}\text { Attach. } \\
\text { Appendix } \\
\text { Only }\end{array}$ & $\begin{array}{c}\text { EDT/ECN } \\
\text { Only }\end{array}$ \\
\hline B1-07 & 1 & & & \\
\hline H2 -53 & 1 & & & \\
\hline H7 -15 & 1 & & & \\
\hline R3 -75 & 1 & & & \\
\hline
\end{tabular}




\title{
Feed Delivery Storage and Disposal Mission Summary for 2006 Hot Start
}

\author{
T. J. Davis \\ CH2MHILL Hanford Group, Inc. \\ Richland, WA 99352 \\ U.S. Department of Energy Contract DE-AC06-99RL14047

$\begin{array}{ll}\text { EDT/ECN: } 625316 & \text { UC: } 721 \\ \text { Cost Center: } 7 C 400 & \text { Charge Code: } 106412 \\ \text { B\&R Code: } & \text { Total Pages: } 2\end{array}$

Key Words:

Level One Logic, WED

\begin{abstract}
:
This is the level one River Protection Project (RPP)/Waste Feed Delivery logic diagram for Feed Delivery Storage and Disposal Mission Summary for 2006 Hot Start.
\end{abstract}

TRADEMARK DISCLAIMER. Reference herein to any specific commercial product, process, or service by trade name, trademark, manufacturer, or otherwise, does not necessarily constitute or imply its endorsement, recommendation, or favoring by the United States Government or any agency thereof or its contractors or subcontractors.

Printed in the United States of America. To obtain copies of this document, contact: Document Control Services, P.O. Box 950, Mailstop H6-08, Richland WA 99352, Phone (509) 372-2420; Fax (509) 376-4989.
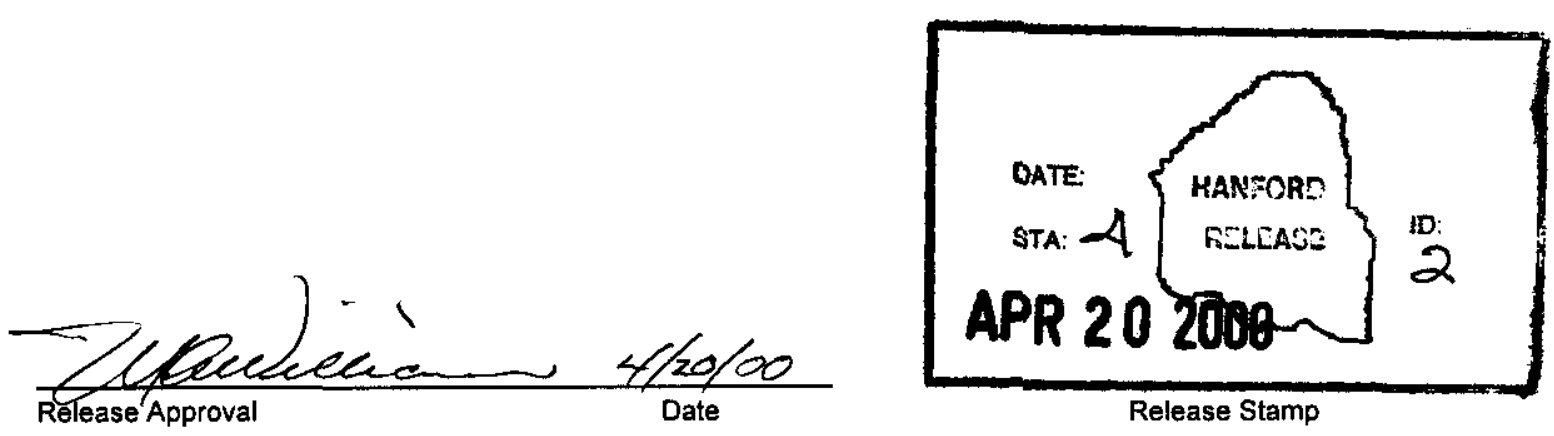

\section{Approved For Public Release}




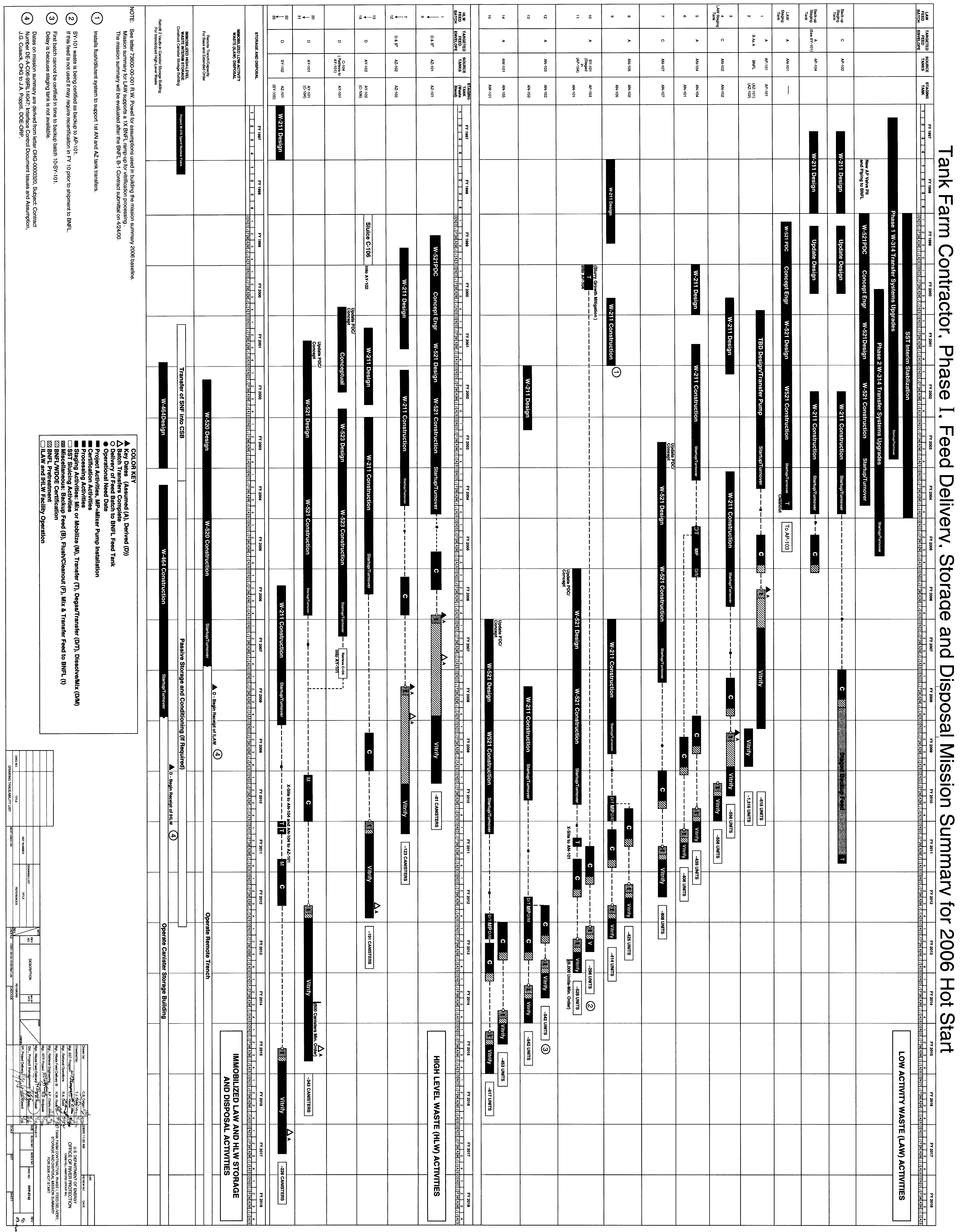

